
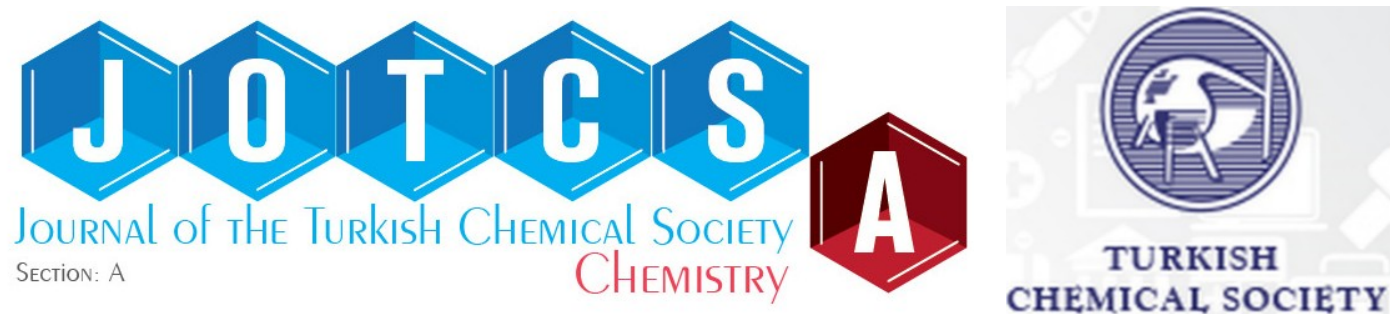

\title{
Chemical compounds, antioxidant properties, and antimicrobial activity of olive leaves derived volatile oil in West Anatolia
}

\author{
Nilüfer Vural ${ }^{1,2} \triangle\left(D\right.$, M. Abdülkadir AKAY ${ }^{3} D$ \\ ${ }^{1}$ University of Ankara Yıldırım Beyazıt, Vocational School, Department of Food Processing-Food Technology, \\ Çubuk, Ankara, Turkey \\ ${ }^{2}$ University of Ankara Yıldırım Beyazıt, Institute of Public Health, Department of Traditional, \\ Complementary and Integrative Medicine Practice and Research Center, Etlik, Ankara, Turkey \\ ${ }^{3}$ University of Ankara, Faculty of Science, Department of Chemistry, Tandogan, Ankara 06100, Turkey
}

\begin{abstract}
In this article, the chemical compounds, antimicrobial and antioxidant activity of the volatile oil from leaves of Olea europaea L. cultivar from Turkey (Ayvalık) has been studied. The essential oil was provided with a Clevenger apparatus and analyzed by GC-MS/FID. This analysis leads to the detection of 42 compounds representing $99.59 \pm 1.15 \%$ of the total oil. The major constituents were a-pinene $(9.82 \pm 0.33 \%)$, benzylalcohol $(8.83 \pm 0.27 \%)$, phenethylalcohol $(8.52 \pm 0.25 \%)$, 2-monopalmitin $(8.13 \pm 0.28 \%)$, palmitic acid $(5.53 \pm 0.41 \%)$, octadecanoic acid 2,3-dihydroxypropylester $(5.84 \pm 0.42 \%)$, phytol $(4.22 \pm 0.17 \%)$, and benzaldehyde $(4.21 \pm 0.38 \%)$. The antimicrobial activities of the dried leaves essential oils were assessed against seven bacterial and four fungal strains. Significantly, the essential oil has an efficient antibacterial activity toward to the bacterial strains such as Bacillus cereus ATCC 14579, Candida albicans ATCC 10231, Enterococcus faecalis ATCC 29212 and Klebsiella pneumoniae ATCC 13883. The olive a leaf essential oils showed significant antimicrobial and antioxidant effects. This study gives more knowledge for the development of this crucial therapeutic plant.
\end{abstract}

Keywords: Olea europaea L. Leaves volatile oils, GC-MS/FID, Chemical composition, Antimicrobial activity, Antioxidant activity

Submitted: November 29, 2020. Accepted: March 17, 2021.

Cite this: Vural N, Akay MA. Chemical compounds, antioxidant properties, and antimicrobial activity of olive leaves derived volatile oil in West Anatolia. JOTCSA. 2021;8(2):511-8.

DOI: https://doi.org/10.18596/jotcsa.833139.

*Corresponding author. e-mail: nvural71@gmail.com, n.vural@ybu.edu.tr.

\section{INTRODUCTION}

Olea europaea L. is one of the most important fruit trees in Mediterranean countries, especially in Spain, Italy, France, Greece, Turkey, Tunisia, and Morocco (1). In Turkey, Ayvalık region of the Balıkesir province has the most plentiful olive variety representing more than $19 \%$ of in Turkey's whole olive trees.

Olive leaf is the origin of many phytochemicals such as polyphenolics and flavonoids, which accomplish many antioxidant, antibacterial, antifungal, and anti-inflammatory activity (2-10). In folk medicine, it is reported that the decoction prepared from the leaves is used for hypertension, arrhythmia, intestinal muscle spasms, and cancer treatment (11-14). In Turkey, congenital coronary artery anomalies are commonly seen at the rate of $0.2-$ $1.2 \%$. Coronary artery anomalies such as angina, significant hemodynamic abnormalities and myocardial infarction are essential because of the occurrence and sudden death (15).

Essential oils possess specific volatile odors or flavors obtained from various plant parts like 
flowers, seeds, and leaves. Essential oils with various chemical components such as phenols, flavones, flavonoids, and terpenes, etc. show antibacterial, anti-cancer, antifungal, and antioxidant activities (16).

There are very few studies on the extract obtained by hydrodistillation of Olea europaea L. leaves and its essential oil content, antioxidant and antimicrobial effect in the literature. This study's primary purpose was to identify the constituents of Olea europaea L. essential oil by GC/MS spectrometric method and investigate the chemical characterization, antioxidant, and antimicrobial activities of the volatile oil from Ayvalık flora of Turkey.

\section{EXPERIMENTAL SECTION}

\section{Plant material}

Fresh leaves of Olea europaea L. cv. were picked up in October 2017 from Ayvalık (Turkey), a region in Balıkesir Province on the Aegean Sea coast located at $39^{\circ} 16^{\prime} 40.55 \mathrm{~N}$ and $26^{\circ} 42^{\prime} 47.77 \mathrm{E}$. The Mediterranean climate is dominant in this region, characterized by hot and dry summers and mild and rainy winters. The mean temperature is between 24-34 ${ }^{\circ} \mathrm{C}$. West winds from the weather cool the region. The average annual rainfall is about 700 $\mathrm{mm}$. The altitude of the region is $270 \mathrm{~m}$.

The voucher specimen was described and stocked at Herbarium Turcicum, Ankara Herbarium Voucher No: 60542 (Department of Biology, Ankara University, Ankara, Turkey). Part of the leaves was washed, cleaned, and shade-dried at room temperature without an airflow $\left(25^{\circ} \mathrm{C}\right)$ for 15 days. After drying, olive leaf samples were milled and became ready for hydrodistillation.

\section{Isolation of the volatile oils}

The volatile oils were obtained by hydrodistillation in a Clevenger-type apparatus from Olea europaea L. leaves. To get a colorful oil with a yield of $0.06 \%$ $(\mathrm{w} / \mathrm{w})$, each dried sample $(200 \mathrm{~g})$ consisted of the leaves of upper branch parts of the plants were exposed to water $(500 \mathrm{~mL})$ distillation in a Clevenger apparatus for $3.5 \mathrm{~h}$. The gained volatile oil was dried over anhydrous $\mathrm{Na}_{2} \mathrm{SO}_{4}$, then filtered evaporated, and concentrated under a gentle stream of $\mathrm{N}_{2}$ (nitrogen gas) and stored at $4{ }^{\circ} \mathrm{C}$ until analyzed.

\section{Volatile oil analysis}

GC analyses were made with a Shimadzu (Kyoto, Japan) GC17B instrument equipped with TC-5 capillary column $(50 \mathrm{~m} \times 0.25 \mathrm{~mm}$, film thickness $0.25 \mu \mathrm{m})$. The working conditions: oven temperature program consisted of a $10-\mathrm{min}$ hold at $60{ }^{\circ} \mathrm{C}$, followed by a $5{ }^{\circ} \mathrm{C} / \mathrm{min}$ rise to $220{ }^{\circ} \mathrm{C}$. The injector and FID detector temperature were maintained at $250{ }^{\circ} \mathrm{C}$. The detector carrier gas was nitrogen ( $2 \mathrm{~mL} / \mathrm{min})$, FID split ratio was $1: 25$, and injection volume was $1 \mu \mathrm{L}$. The identification of the components was made by comparing their retention times with those of pure authentic samples. Simultaneously, linear retention indices (LRI) according to $\mathrm{n}$-alkane series were also evaluated for component identification $(1,17)$. Relative amounts of the individual components were calculated based on GC peak areas with FID response factor correction. The oil samples were analyzed by direct, splitless injection.

A Shimadzu (Kyoto, Japan) GC/MS QP2010 apparatus via the capillary column (TC-5/MS; $50 \mathrm{~m}$ $x 0.25 \mathrm{~mm}$ i.d. film thickness $0.25 \mu \mathrm{m}$ ) equipped with electron ionization quadrupole detector $(\mathrm{m} / \mathrm{z}$ 35-650) was used to determine the chemical composition of the samples. $1.2 \mathrm{~mL} / \mathrm{min}$ flow rate for the carrier helium gas, $240{ }^{\circ} \mathrm{C}$ for injection heat, and $290{ }^{\circ} \mathrm{C}$ temperatures for the MS transfer line was selected. The column temperature was initially set at $50{ }^{\circ} \mathrm{C}$ and held for $3 \mathrm{~min}$., then increased to $280{ }^{\circ} \mathrm{C}$ at the rate of $3{ }^{\circ} \mathrm{C} / \mathrm{min}$. and fit for $5 \mathrm{~min}$ at that temperature. Diluted samples $(1: 15[\mathrm{v} / \mathrm{v}]$, in acetone) of $1.0 \mu \mathrm{L}$ amounts were injected in a splitless manner.

The constituents were identified based on comparing their mass spectra with those of NBS75K, Wiley 7, NIST MS 2.0 library search data of the GC-MS system, standards of the main components, and literature data.

\section{Total antioxidant activity (TAA)}

$D P P H$ (diphenylpicrylhydrazyl) assay

The TAA of the volatile fraction was measured by the reduction of alcoholic DPPH solutions in the existence of an electron-donating antioxidant (EDA) by modifying the method described by Gil et al. (18). Briefly, $100 \mu \mathrm{L}$ aliquots of various concentrations of the volatile olive leaf extracts were added to $2.9 \mathrm{~mL}$ of a 2,2-diphenyl-1picrylhydrazyl (DPPH; $6.10^{-5} \mathrm{M} \mathrm{DPPH;} 2.4 \mathrm{mg} / 100$ $\mathrm{mL}$ of methanol). After a $40 \mathrm{~min}$. incubation at $30{ }^{\circ} \mathrm{C}$ temperature in the dark, the absorbance was read at $520 \mathrm{~nm}$. Percentage inhibition of free radical DPPH was calculated in the following manner:

$$
\text { Inhibition } \%=\left[\left(\mathrm{A}_{\text {control }}-\mathrm{A}_{\text {sample }}\right) / \mathrm{A}_{\text {control }}\right] \times 100
$$

where $A_{\text {control }}$ is the absorbance of the control and $A_{\text {sample }}$ is the absorbance of the sample.

The volatile oil concentration providing $50 \%$ inhibition $\left(\mathrm{IC}_{50}\right)$ was calculated from the graph plotting of inhibition free radical DPPH in percentage (\%) against essential oil concentration. As a positive control, butylated hydroxytoluene (BHT), a synthetic 
antioxidant reagent, was used. All tests were carried out in triplicate.

\section{Antimicrobial activity (AmA)}

Source of Microorganisms

The bacterial strains tested were Bacillus cereus ATCC 14579, Enterococcus faecalis ATCC 29212, Escherichia coli ATCC 25922, Klebsiella pneumoniae ATCC 13883, Lactobacillus plantarum ATCC 8014, Pseudomonas aeruginosa ATCC 15442 and Staphylococcus aureus ATCC 27950. In the case of yeasts, Candida albicans ATCC 10231, Candida glabrata ATCC 90030, Candida kreusei ATCC 34077, and Candida parapsilosis ATCC 22019. All these cultures were purchased from the culture collections of the National Type Culture disperse Collection Unit, Microbiology Reference Laboratory and Biological Products Department, Public Health General Directorate, Ministry of Health, (Ankara, Turkey).

\section{Disc Diffusion Method}

All method steps, including preparation conditions of test microorganisms, inoculation instructions, bacteria and yeast incubation times, were studied according to Vardar-Ünlü et al., (19). Briefly, a suspension of the test micro-organism $(0.1 \mathrm{~mL}, 108$ cells $\mathrm{mL}^{-1}$ ) was spread on solid medium plates. Filter paper discs (6 $\mathrm{mm}$ in diameter) (Schleicher and Schüll, No.2668, Germany) were soaked with $30 \mu \mathrm{L}$ of the oil and placed on the inoculated plates. After keeping the plates at $4{ }^{\circ} \mathrm{C}$ for $2 \mathrm{~h}$, they were incubated at $37{ }^{\circ} \mathrm{C}$ for $24 \mathrm{~h}$ (bacteria) or at $30{ }^{\circ} \mathrm{C}$ for $48 \mathrm{~h}$ (yeasts). Following the incubation period, the diameters $(\mathrm{mm})$ of the inhibition zones were measured. The diameters $(\mathrm{mm})$ of the inhibition zones were quantified, and the results were classified into three categories according to the diameters obtained in the test: resistant $(>7 \mathrm{~mm})$, medium (>12 mm) and sensitive (> $18 \mathrm{~mm}$ ) (20).

\section{Minimum inhibitory concentration (MIC) Method}

A microdilution broth susceptibility assay for bacteria and yeast was used to determine the MIC (21). Preparation, incubation, and counting of bacterial strains, yeasts, and test strains were performed consistent with the method of Ünlü et al. (22). All tests were performed in Mueller Hinton broth (MHB; BBL) supplemented with Tween 80 detergent (final concentration of $0.5 \%, \mathrm{v} / \mathrm{v}$ ) to enhance the oil solubility. Bacterial strains were cultured overnight at $37{ }^{\circ} \mathrm{C}$ in $\mathrm{MHA}$ and the yeasts were cultured overnight at $30{ }^{\circ} \mathrm{C}$ in Sabouraud dextrose broth (SDB). Test strains were suspended in MHB to give a final density of $5 \times 10^{5}$ colonyforming units (CFU)/mL and were confirmed by viable counts. The essential oil's geometric dilutions were prepared in a 96-well microtiter plate, including one growth control (MHB + Tween 80) and one sterility control (MHB + Tween $80+$ test oil). Plates were incubated under normal atmospheric conditions at $37{ }^{\circ} \mathrm{C}$ for $24 \mathrm{~h}$ for bacteria and at $30{ }^{\circ} \mathrm{C}$ for $48 \mathrm{~h}$ for the yeasts. British Society for Medical Mycology (BSMM) guidelines were used for broth microdilution testing for yeasts. The essential oil was resolved in Yeast Nitrogen Base Glucose (YNBG) supplemented with Tween 80 detergent (final concentration $0.5 \% \mathrm{v} / \mathrm{v}$ ) and ultimate concentrations ranged from $100.00 \mathrm{mg} / \mathrm{mL}$ to 0.025 $\mathrm{mg} / \mathrm{mL}(22)$.

\section{Statistical Analysis}

The data were statistically analyzed by ANOVA $(n=3)$ and statistical significance was accepted at a level of $p<0.05(23)$

\section{RESULTS AND DISCUSSION}

\section{Chemical Composition of volatile oil}

The composition of Olea europaea L. volatile oil was analyzed by GC-MS. 42 compounds, representing $99.59 \pm 1.15 \%$ of the oil, were identified. The main components are a-pinene $(9.82 \pm 0.33 \%)$, benzyl alcohol $(8.83 \pm 0.27 \%)$, phenethyl alcohol $(8.52 \pm 0.25 \%)$, 2-monopalmitin $(8.13 \pm 0.28 \%)$, palmitic acid $(5.53 \pm 0.41 \%)$, octadecanoic acid 2,3dihydroxypropyl ester $(5.84 \pm 0.42 \%)$, phytol $(4.22 \pm 0.17 \%)$, benzaldehyde $(4.21 \pm 0.38 \%)$ (Table $1)$. In our study, alcohols were characterized by the presence of eleven compounds $(32.92 \pm 0.56 \%)$, the most important of them were benzyl alcohol $(8.83 \pm 0.27 \%)$, phenethyl alcohol (8.52 $\pm 0.25 \%)$, followed by phytole $(4.22 \pm 0.17 \%)$. The second priority group was aldehydes composed of five compounds $(9.42 \%)$ mainly, benzaldehyde $(4.21 \pm 0.38 \%)$ and, 2,4-heptadienal (2.91 $\pm 0.23 \%)$. The ester group was characterized by 2monopalmitin $(8.13 \pm 0.28 \%)$. 
Table 1. The main leaf volatiles (\%) of Olea europea L. collected in the Ayvalık, Turkey.

\begin{tabular}{|c|c|c|c|c|c|}
\hline & Constituents & LRI ${ }_{\text {lit. }}$ & LRI cal. & $\%$ & $\begin{array}{c}\text { Method of } \\
\text { identification }\end{array}$ \\
\hline \multirow{11}{*}{ Alcohols } & 1-penten-3-ol & 683 & 678 & $1.81 \pm 0.09$ & MS \\
\hline & 2-ethoxyethanol & 717 & 715 & $2.22 \pm 0.22$ & MS \\
\hline & cis-3-hexene-1-ol & 857 & 860 & $1.23 \pm 0.07$ & MS \\
\hline & trans- 2-hexene-1-ol & 868 & 870 & $2.62 \pm 0.24$ & $\mathrm{CO}, \mathrm{MS}$ \\
\hline & 1-hexanol & 884 & 881 & $1.21 \pm 0.09$ & $\mathrm{CO}, \mathrm{MS}$ \\
\hline & Benzyl alcohol & 1007 & 1005 & $8.83 \pm 0.27$ & MS \\
\hline & Phenethyl alcohol & 1110 & 1112 & $8.52 \pm 0.25$ & MS \\
\hline & p-cymen-8-ol & 1183 & 1187 & $0.72 \pm 0.11$ & $\mathrm{CO}, \mathrm{MS}$ \\
\hline & Eugenol & 1356 & 1350 & $0.33 \pm 0.02$ & $\mathrm{CO}, \mathrm{MS}$ \\
\hline & Isoeugenol & 1384 & 1388 & $1.21 \pm 0.09$ & $\mathrm{CO}, \mathrm{MS}$ \\
\hline & Phytol & 1840 & 1841 & $4.22 \pm 0.17$ & $\mathrm{CO}, \mathrm{MS}$ \\
\hline \multirow{5}{*}{ Aldehydes } & n-Hexanal & 784 & 785 & $0.73 \pm 0.12$ & $\mathrm{CO}, \mathrm{MS}$ \\
\hline & Benzaldehyde & 996 & 998 & $4.21 \pm 0.38$ & MS \\
\hline & 2,4-heptadienal & 1009 & 1008 & $2.91 \pm 0.23$ & MS \\
\hline & n-octanal & 1023 & 1022 & $0.23 \pm 0.02$ & MS \\
\hline & Nonanal & 1098 & 1100 & $1.34 \pm 0.08$ & $\mathrm{CO}, \mathrm{MS}$ \\
\hline Esters & 2-Monopalmitin & 2498 & 2493 & $8.13 \pm 0.28$ & $\mathrm{CO}, \mathrm{MS}$ \\
\hline \multirow[b]{2}{*}{ Terpenes } & a- pinene & 941 & 968 & $9.82 \pm 0.33$ & $\mathrm{CO}, \mathrm{MS}$ \\
\hline & $\beta$ - caryophyllene & 1421 & 1420 & $2.01 \pm 0.18$ & MS \\
\hline \multirow{6}{*}{ Carb. Acids } & Hexanoic acid & 1085 & 1092 & $0.42 \pm 0.03$ & MS \\
\hline & Caprylic acid & 1179 & 1182 & $0.64 \pm 0.05$ & $\mathrm{MS}$ \\
\hline & Nonanoic acid & 1280 & 1280 & $0.72 \pm 0.12$ & MS \\
\hline & Myristic acid & 1720 & 1718 & $0.71 \pm 0.11$ & MS \\
\hline & Palmitic acid & 1973 & 1968 & $5.53 \pm 0.41$ & MS \\
\hline & Stearic acid & 2124 & 2125 & $1.32 \pm 0.07$ & $\mathrm{CO}, \mathrm{MS}$ \\
\hline \multirow{10}{*}{ Hydrocarbons } & $2,2,6$-trimethyloctane & 1029 & 1030 & $2.44 \pm 0.22$ & $\mathrm{CO}, \mathrm{MS}$ \\
\hline & Undecane,5-methyl & 1154 & 1157 & $0.23 \pm 0.02$ & $\mathrm{CO}, \mathrm{MS}$ \\
\hline & Dodecane,4,6-dimethyl & 1285 & 1288 & $1.22 \pm 0.06$ & MS \\
\hline & $\mathrm{n}$-Tetradecane & 1399 & 1400 & $1.53 \pm 0.06$ & MS \\
\hline & n-Hexadecane & 1600 & 1601 & $1.82 \pm 0.07$ & MS \\
\hline & n-Heptadecane & 1700 & 1700 & $0.82 \pm 0.11$ & MS \\
\hline & 1-chloro octadecane & 2070 & 2068 & $1.47 \pm 0.09$ & MS \\
\hline & Heneicosane & 2100 & 2100 & $0.94 \pm 0.08$ & MS \\
\hline & Tetracosane & 2500 & 2501 & $0.88 \pm 0.05$ & MS \\
\hline & $\begin{array}{l}\text { Octadecanoic acid, } \\
\text { dihydroxypropyl ester }\end{array}$ & 2689 & 2690 & $5.84 \pm 0.42$ & MS \\
\hline \multirow{8}{*}{ Others } & 1-hydroxy-2-propanone & 698 & 695 & $0.93 \pm 0.08$ & MS \\
\hline & Trichloroethene & 702 & 698 & $0.47 \pm 0.02$ & $\mathrm{CO}, \mathrm{MS}$ \\
\hline & 4-Ethenylpyridine & 1037 & 1040 & $2.25 \pm 0.18$ & MS \\
\hline & Methyldiethanolamine & 1053 & 1055 & $1.53 \pm 0.07$ & MS \\
\hline & 5-chloro-n- amylacetate & 1129 & 1131 & $1.34 \pm 0.04$ & MS \\
\hline & 4-Ethenyl-2-methoxyphenol & 1283 & 1284 & $1.32 \pm 0.05$ & MS \\
\hline & Benzene, (2-propenyloxy) methyl & 1405 & 1404 & $2.92 \pm 0.23$ & MS \\
\hline & Total identified & & & $99.59 \pm 1.15$ & \\
\hline
\end{tabular}

LRI: linear retention indices (HP5-MS column); MS, mass spectrometry; CO, co-injection with standards; LRI lit $_{\text {, }}$ retention indices from the literature $(10) ; L_{\text {calc }}$ experimental retention indices calculated against a $C_{8}-C_{32} n-$ alkanes mixture on the HP5-MS column

All values are mean \pm standart deviation of triplicates.

We were able to find a limited number of articles associated with the essential oil compositions of Olea europaea L. $(1,24-28)$. In several previous studies, the chemical composition of the volatile fractions from Olea europaea L. cultivars was investigated. Most of these studies focused on the regions, showing similar climatic and geographic characteristics of the Mediterranean basin. In one of these researches, three Italian Olea europaea L. cultivars (Leccino, Frantoio, and Cipressino) were investigated in different years and months (July and November) by Campeol et al. (24, 25). In a Tunisian investigation, Chemlali cultivar was studied by Haloui et al. (26) and Nebjemel, Chemchali, Chemlali and Chetou cultivars were studied in October by Brahmi et al. $(1,27)$.

In the northern part of Algeria, olive leaves collected in September at an altitude of $800 \mathrm{~m}$ were investigated (28). The essential constituents in either plant were determined as (E)-2-hexenal, nonanal, kongol, benzene-acetaldehyde, (E)- $\beta$ - 
damascone,

(E)- $\beta$-damascenone,

$(\mathrm{E}, \mathrm{E})-\mathrm{a}-$

farnesene and (E)-2-hexen-1-ol $(24,25)$. The main components were found as (E)-3-hexenol, 3ethenylpyridine, phenylethyl alcohol (1).

Brahmi et al. (27) have identified the compounds forming $92.10 \%$ of the total volatile oil. Consistent with our study, Brahmi et al. (27) determined that there was the highest amount (6.10\%) of phenylethyl alcohol in the alcoholic group, which was characterized by the presence of four compounds. Aldehydes were composed of nine compounds, primarily nonanal. Volatile compounds, characterizing at least $99.23 \%$ of the essential oils, were identified as a-pinene $(52.70 \%)$, 2.6-dimethyl-octane (16.57\%) being the most abundant components of the essential oil. The other chemical components were 2-methoxy3 -isopropylpyrazine $(6.01 \%)$, tetracosane $(4.38 \%)$ and docosane (3.58\%). The following chemical components occurred in trace amounts: $\beta$-pinene $(2.46 \%), \quad z-3-$ hexanol (1.51\%), ( $E, Z)-2,6-$ nonadienal $(1.46 \%)$, a-ionone $(1.45 \%)$ and $(E)-2$ hexanol $(1.26 \%)(26)$.

Boukhebti et al. (28) have analyzed and identified the volatile oil components of Olea europaea leaves which represent $94.10 \%$ of the total oil. The chemical composition of the essential oil is dominated by the compounds, palmitic acid $(14.71 \%)$, Z-nerolidol $(9.45 \%)$ and octacosane $(6.32 \%)$.

Keskin et al. (29) reported that the chemical constitutions of aqueous extract (using a Soxhlet apparatus) from West Anatolia, Turkey were analyzed by GC/MS. GC/MS analysis of the extract resulted in the identification of fifteen constituents, representing $99.68 \%$ of the extracts; cyclotrisiloxane, hexamethyl (36.98\%), cyclotetrasiloxane, octamethyl (15.18\%) and cyclopentasiloxane, decamethyl (14.59\%) being the main components.

In other articles focusing on the same cultivars or different cultivars growing in particular habitats, the role of environmental effects are studied and its importance is emphasized. Further investigations would probably explain and generalize the obtained data.

Total antioxidant activity (TAA) of volatile oil

The weakest TAA was exhibited by the volatile oil $70.68 \pm 2.4 \%$ and $3080 \pm 11.2 \mathrm{IC}_{50}(\mu \mathrm{g} / \mathrm{mL})$ (Table $2)$. The activities were compared with BHT. The volatiles of the dried leaves showed tolerable TAA and lower than the reference antioxidant, BHT $\left(\mathrm{IC}_{50}=28.8 \pm 1.4 \mu \mathrm{g} / \mathrm{mL} ; 85.12 \pm 4.8 \%\right.$ ).

This observation is consistent with the other reports. In previous studies on the dried olive leaves, it is shown that DPPH $\mathrm{IC}_{50}(\mu \mathrm{g} / \mathrm{mL})$ values vary in different cultivars. Brahmi et al. (1) reported that DPPH values were found $3430.70 \pm 51.36(\mu \mathrm{g} / \mathrm{mL}), 3190.52 \pm 89.50(\mu \mathrm{g} / \mathrm{mL})$ and $3250.11 \pm 46.52(\mu \mathrm{g} / \mathrm{ml})$ respectively. Brahmi et al. (27) described that the essential oil exhibited the weakest TAA $(49.92 \%)$, Haloui et al. (26) reported that the TAA was exhibited by the essential oil $(74.44 \% \pm 0.79)$.

Table 2. Antioxidant activity of the essential oil of Olea europaea $L$.

\begin{tabular}{l|c|c}
\hline Sample & $\begin{array}{c}\text { DPPH radical } \\
\text { scavenging } \\
\text { activity, } \%\end{array}$ & $\begin{array}{c}\text { DPPH } \\
\mathbf{I C}_{\mathbf{5 0}}(\boldsymbol{\mu g} / \mathbf{m L})\end{array}$ \\
\hline Essential oil of Olea europaea L leaves & $70.68 \pm 2.40$ & $3080.00 \pm 11.22$ \\
\hline BHT & $85.12 \pm 4.80$ & $28.20 \pm 1.40$ \\
\hline
\end{tabular}

Results are means of three different experiments.

Antimicrobial activity (AmA) of volatile oil The AmA of the volatile oil was examined for 7 bacteria and 4 Candida species using disk diffusion and MIC methods. (Table 3). Comparing the essential oils with the control antibiotic and control antifungal concluded that they could inhibit most bacterial growths with different effectiveness. 
Table 3. Antimicrobial activity of essential oil from Olea Europea L. leaves.

\begin{tabular}{|c|c|c|c|c|}
\hline \multirow[b]{2}{*}{ Microorganisms } & \multicolumn{4}{|c|}{ Olea europaea $L$. essential oil } \\
\hline & Disc Diffusiona & $\begin{array}{l}\text { MIC values } \\
(\mu g / m L)\end{array}$ & $\begin{array}{c}\text { Amphotericin } \\
\text { (Control Antifungal) }\end{array}$ & $\begin{array}{l}\text { Gentamicin } \\
\text { (Control } \\
\text { Antibiotic) }\end{array}$ \\
\hline Bacillus cereus ATCC 14579 (+) & $29.00 \pm 0.50$ & 1100 & nd & 1500 \\
\hline Enterococcus faecalis ATCC 29212 & $13.00 \pm 0.01$ & 1750 & nd & 2100 \\
\hline Escherichia coli ATCC 25922 & $9.00 \pm 0.09$ & 70 & nd & 1750 \\
\hline Klebsiella pneumoniae ATCC 13883 & $11.00 \pm 0.02$ & 1500 & nd & 2250 \\
\hline Lactobacillus plantarum ATCC 8014 (+) & $9.00 \pm 0.03$ & 50 & nd & 750 \\
\hline Pseudomonas aeruginosa ATCC 15442 & $13.00 \pm 0.05$ & 150 & nd & 1100 \\
\hline Staphylococcus aureus ATCC $27950(+)$ & $10.00 \pm 0.04$ & 70 & nd & 2100 \\
\hline Candida albicans ATCC 10231 & $17.00 \pm 0.11$ & 1250 & 600 & nd \\
\hline Candida glabrata ATCC 90030 & $9.00 \pm 0.15$ & 150 & 550 & nd \\
\hline Candida kreusei ATCC 34077 & $7.00 \pm 0.06$ & 250 & 500 & nd \\
\hline Candida parapsilosis ATCC 22019 & $7.00 \pm 0.21$ & - & 450 & nd \\
\hline \multicolumn{5}{|c|}{ 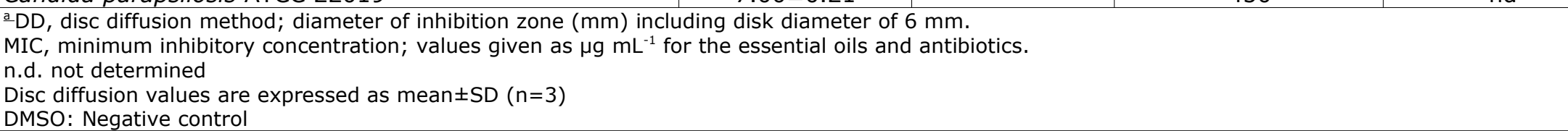 } \\
\hline
\end{tabular}


This study revealed that the volatile oil has efficient antibacterial activity toward bacterial strains, especially Bacillus cereus ATCC 14579, Candida albicans ATCC 10231, Enterococcus faecalis ATCC 29212, Pseudomonas aeruginosa ATCC 15442, Klebsiella pneumoniae ATCC 13883, Staphylococcus aureus ATCC 27950, Candida glabrata ATCC 90030. On the flip side, there is an inference that the essential oil's antimicrobial activity (resistant $>7 \mathrm{~mm}$ ) has no significant effect on Candida kreusei ATCC 34077 and Candida parapsilosis ATCC 22019. Susceptibility of the oil, amphotericin (control antifungal) and, gentamicin (control antibiotic) was expressed as a minimum inhibitory concentration (MIC) and, DMSO was used as a negative control.

Brahmi et al. (1) also analyzed the AmA of dried olive leaves. They found that essential oil has very remarkable antibacterial activity towards bacterial strains E. faecalis ATCC 2921270 S. aureus ATCC 27950 E. coli ATCC 25922 P. aeruginosa ATCC27950 C. Kreusei ATCC6258 C. parapsilosis ATCC C. albicans ATCC90028 C. glabrata ATCC90030. While Boukhebti et al. (21) established similar results with Citrobacter freundii ATCC 8090, Pseudomonas aeruginosa ATCC 27853 and, Staphylococcus aureus ATCC 25923, while not having great antibacterial activity against Bacillus subtilis ATCC 6633 and Escherichia coli ATCC 25922.

\section{CONCLUSION}

Olive leaves are considered a by-product of the olive tree cultivation and oil industry. Interest in alternative uses of these agro-food by-products has increased significantly in recent years. Endowed with engaging biological activities, many studies focused on valorizing olive leaves in the food industry as a functional food or as a source of nutraceuticals.

In this study, to our knowledge, the antioxidant and antimicrobial activities of the essential oil obtained from the olive leaves in West Anatolia in Turkey were tested for the first time. According to the results obtained from this work, the volatile compounds of dried olive leaves have very high, antibacterial and antifungal properties that may benefit the pharmaceutical, food, and cosmetics industries. It has been determined that especially essential oils have a very impressive antibacterial activity against bacterial strains such as Bacillus cereus ATCC 14579, Candida albicans ATCC 10231, Enterococcus faecalis ATCC 29212 and Klebsiella pneumoniae ATCC 13883. However, the leaves' essential oil showed a lower, tolerable antioxidant activity than the reference antioxidant $\mathrm{BHT}$. On the other hand, it can also be concluded that the changes in the Olea europea L. volatile oil chemical compositions, from different geographical areas, might have been based on different variables, climatic, seasonal, geographical, and geological differences.

\section{COMPLIANCE WITH ETHICAL STANDARDS}

\section{Conflict of interest}

The authors declare no conflict of interest.

\section{REFERENCES}

1. Brahmi F, Flamini G, Issaoui M, Dhibi M, Dabbou S, Mastouri M, Hammami $M$. Chemical composition and biological activities of volatile fractions from three Tunisian cultivars of olive leaves. Medicinal Chemistry Research. 2012; 21(10): 2863-72. Doi: 10.1007/s00044-011-9817-8

2. Borges A, Jose H, Homem V, Simoes M. Comparison of techniques and solvents on the antimicrobial and antioxidant potential of extracts from Acacia dealbata and Olea europaea. Antibiotics. 2020; 9(2): 48. Doi: $10.3390 /$ antibiotics 9020048

3. Debib A, Boukhatem MN. Phenolic content, antioxidant and antimicrobial activities of "Chemlali" olive leaf (Olea europaea L.) extracts. International Journal of Pharmacology, Phytochemistry and Ethnomedicine. 2017; 6:38-46.Doi:10.18052/www.scipress.com/IJPPE. 6.38.

4. Vural N, Algan Cavuldak Ö, Akay MA. D-Optimal design and multi-objective optimization for green extraction conditions developed with ultrasonic probe for oleuropein. Journal of Applied Research on Medicinal and Aromatic Plants. 2021; 20: 100279. Doi: 10.1016/j.jarmap.2020.100279

5. Difonzo G, Squeo G, Pasqualone A, Summo C, Paradiso VM, Caponio F. The challenge of exploiting polyphenols from olive leaves: addition to foods to improve their shelf-life and nutritional value. Journal of the Science of Food and Agriculture. 2020. Doi: 10.1002/jsfa. 10986

6. Nicolì $F$, Negro $C$, Vergine $M$, Aprile $A$, Nutricati $E$, Sabella E, Miceli A, Luvisi A, De Bellis L. Evaluation of phytochemical and antioxidant properties of 15 Italian Olea europaea L. Cultivar Leaves. Molecules. 2019; 24(10): 1998. Doi: 10.3390/molecules24101998

7. Chiaino $E$, Micucci $M$, Cosconati $S$, Novellino $E$, Budriesi R, Chiarini A, Frosini M. Olive leaves and Hibiscus flowers extracts-based preparation protect brain from oxidative stress-induced injury. Antioxidants. 2020; 9(9):806. Doi: 10.3390/antiox9090806

8. Samouh $Y$, Lemrani $A$, Mimouni $H$, Mohamad J, Said AAH. Ethnopharmacological Study of Herbal Medicines used to treat Cancer in Morocco. J Phytopharmacol 2019; 8(3):135-41. Doi:10.31254/phyto.2019.8309

9. Castillo JJ, Alcaraz M, Benavente-Garcia O. Antioxidant and radioprotective effects of olive leaf extract. Olives and olive oil in Health and Disease Prevention. 2010; 12: 951-8. Doi: 10.1016/B978-0-12-374420-3.00102-9

10. Venditti A, Serrilli AM, Rizza L, Frasca G, Cardile V, Bonina FP, Bianco A. Aromadendrine, a new component of the flavonoid pattern of Olea europaea L. and its anti- 
inflammatory activity. Natural Product Research. 2013; 27(4):340-9. Doi: 10.1080/14786419.2012.693924

11. Khayyal MT, El-Ghazaly MA, Abdallah DM,.Nassar NN Okpanyi SN, Kreuter $\mathrm{MH}$. Blood pressure lowering effect of an olive leaf extract (Olea europaea) in L-NAME induced hypertension in rats. Arzneimittel-Forschung/Drug Research, 2002; 52(11):797-802.

12. Agalias A, Melliou E, Magiatis P, Mitaku S, Gikas E, Tsarbopoulos A. Quantitation of oleuropein and related metabolites in decoctions of Olea leaves from ten Greek cultivated varieties by HPLC with diode array detection (HPLC-DAD). Journal of Liq. Chr. \& Related Tech. 2005; 28: 1557-71. Doi: 10.1081/JLC-200058355

13. Merrouni IA, Elachouri M. Anticancer medicinal plants used by Moroccan people: Ethnobotanical, preclinical, phytochemical and clinical evidence. Journal of Ethnopharmacology. 2021; 266:113435. Doi:10.1016/j.jep.2020.113435

14.Özcan MM, Matthäus B. A review: benefit and bioactive properties of olive (Olea europaea L.) leaves. European Food Research and Technology. 2017; 243(1): 89-99. Doi: 10.1007/s00217-016-2726-9

15. Çilingiroğlu S. Evaluation of coronary artery anomalies with angiography in Turkish adult population. Turkiye Klinikleri J Cardiovasc Sci. 2009; 21(3):363-9.

16. Upadhyay RK. Evaluation of antibacterial and antifungal activities of olive (Olea europaea) essential oil. International Journal of Green Pharmacy. 2014; 8(3): 1806. Doi: $10.22377 /$ ijgp.v8i3.382

17. Adams RP. Identification of essential oil components by Gas Chromatography/Quadrupole Mass Spectroscopy. 4th ed. Allured Publishing Corp, Carol Stream, IL. ISBN10:1932633219. 2007.

18. Gil MI, Tomás-Barberán F A, Hess-Pierce B, Kader AA. Antioxidant capacities, phenolic compounds, carotenoids, and vitamin $\mathrm{C}$ contents of nectarine, peach, and plum cultivars from California. Journal of Agricultural and Food Chemistry. 2002; 50(17): 4976-82. Doi: $10.1021 /$ jf020136b

19. Vardar-Ünlü G, Ünlü $M$, Dönmez $E$, Vural N. Chemical composition and in vitro antimicrobial activity of the essential oil of Origanum minutiflorum O Schwarz \& $\mathrm{PH}$ Davis. Journal of the Science of Food and Agriculture. 2007; 87(2): 255-9. Doi: 10.1002/jsfa.2708
20. Upadhyay RK. GC-MS analysis and in vitro antimicrobial susceptibility of Foeniculum vulgare seed essential oil. American Journal of Plant Sciences. 2015; 6: 1058-68. Doi: 10.4236/ajps.2015.67110.

21. NCCLS (National Committee for Clinical Laboratory Standards). Performance Standards

for Antimicrobial Susceptibility Testing, 9th International Supplement, M100-S9, Wayne, PA. 1999.

22. Ünlü $M$, Ergene $E$, Ünlü $G$ V, Zeytinoglu H. S, Vural N. Composition, antimicrobial activity and in vitro cytotoxicity of essential oil from Cinnamomum zeylanicum Blume (Lauraceae). Food and Chemical Toxicology. 2010; 48(11): 3274-80. Doi: 10.1016/j.fct.2010.09.001

23. SAS/STAT® 9.1, SAS Institute, SAS User's Guide. SAS Institue Inc., Cary, NC. 2004.

24. Campeol E, Flamini G, Chericoni S, Catalano S, Cremonini R. Volatile compounds from three cultivars of Olea europaea from Italy. Journal of Agricultural and Food Chemistry. 2001; 49(11): 5409-11. Doi: $10.1021 /$ jf010455n

25. Campeol E, Flamini G, Cioni P. L, Morelli I, Cremonini $R$, Ceccarini $L$. Volatile fractions from three cultivars of Olea europaea L. collected in two different seasons. Journal of Agriculture Food Chem. 2003; 51: 1994-9. Doi: $10.1021 / \mathrm{jf0} 26025 \mathrm{u}$

26. Haloui E, Marzouk Z, Marzouk B, Bouftira I, Bouraoui A, Fenina N. 2010. Pharmacological activities and chemical composition of the Olea europaea L. leaf essential oils from Tunisia. Journal of Food Agriculture \& Environment. 8(2): 204-8.

27.Brahmi F, Flamini G, Mechri B, Dhibi M, Hammami M. Antioxidant activity of the leaf volatile oil and extracts of Olea europaea L.Cv. Chetoui from N. Tunisia. Journal of Agricultural and Food Chemistry. 2015; 4(3):1-5. Doi: 10.4172/2324-9323.1000171

28. Boukhebti $H$, Chaker AN, Lograda T, Ramdani M. Chemical and antimicrobial properties of essential oils of Olea europea L. International Journal of Pharmacology \& Toxicology. 2015; 5(1): 42-6.

29. Keskin D, Uğur A, Ceyhan N, Dbeys AD. Antimicrobial activity and chemical constitutions of West Anatolian olive (Olea europaea L.) leave. Journal of Food, Agriculture \& Environment. 2012; 10(2): 99-102. 